\title{
Classificações epistemológicas na educação física: redescrições...
}

\author{
Felipe Quintão Almeida* \\ Valter Bracht** \\ Alexandre $\mathrm{Vaz}^{* * *}$
}

\begin{abstract}
Resumo: O artigo oferece uma redescrição de duas classificações epistemológicas bastante utilizadas na Educação Física: a) uma que considera a produção do conhecimento organizada em torno de três matrizes teóricas (empírico-analítica, fenomenológico-hermenêutica e críticodialética); b) e outra que opõe modernos e pós-modernos no debate epistemológico da área. Além disso, analisa a atualidade de ambas quando se considera a hodierna configuração teórica e política do campo bem como quando se opera uma leitura mais nuançada de determinadas perspectivas que integram as classificações em tela. Após apresentar as insuficiências e os limites dessas classificações, desabonando os rótulos a partir delas desencadeados, argumenta que a complexidade e a interpenetração das diferentes correntes teóricas indicam maior cautela na elaboração e uso das mesmas.
\end{abstract}

Palavras-Chave: Educação Física. Epistemologia. Pósmodernismo. Linguagem.

\section{INTRODUÇÃO}

Diferentemente do que aconteceu no debate epistemológico das décadas de 1980 e 1990, quando a discussão concentrou-se, respectivamente, na crise/crítica político-ideológica e na crise/crítica em torno da identidade epistemológica da disciplina (a Educação

\footnotetext{
"Departamento de Ginástica. Centro de Educação Física e Desportos. Universidade Federal do Espírito Santo. Vitória, Espírito Santo. Brasil E-mail: fqalmeida@hotmail.com

"Departamento de Ginástica. Centro de Educação Física e Desportos. Universidade Federal do Espírito Santo. Vitória, Espírito Santo. Brasil. E-mail: valter.bracht@pq.cnpq.br

"'Departamento de Metodologia de Ensino. Centro de Educação. Universidade Federal de Santa Catarina. Florianópolis, Santa Catarina. Brasil. E-mail: alexfvaz@uol.com.br
} 
Física é ou não é ciência? Qual o tipo de relação que a Educação Física deveria estabelecer com a ciência? Qual o tipo de ciência predominante na Educação Física?), a atividade epistemológica em Educação Física (FENSTERSEIFER, 2006) no século XXI tem apresentado um caráter mosaico. Não é difícil chegar a essa conclusão, se em retrospectiva observarmos as temáticas centrais das cinco edições do "Colóquio de Epistemologia de Educação Física", realizadas a cada dois anos, a partir de 2002, pelo Grupo de Trabalho Temático (GTT) Epistemologia, do Colégio Brasileiro de Ciências do Esporte (CBCE). Nesse contexto, algumas classificações epistemológicas, sobejamente conhecidas no campo da Educação Física/Ciências do Esporte, foram retomadas e/ou atualizadas, ao mesmo tempo em que outras foram produzidas e apresentadas à comunidade.

Neste artigo analisamos a atualidade e/ou a pertinência de duas dessas classificações epistemológicas (e dos rótulos que desencadeiam): uma que divide as concepções de ciência na área em três matrizes (empírico-analítica, fenomenológico-hermenêutica e crítico-dialética) e a outra que polariza moderno e pós-moderno na atividade epistemológica da Educação Física. Ocupamo-nos, separadamente, de cada uma delas. A descrição que oferecemos, em cada um dos dois tópicos do artigo, procura demonstrar como essas classificações, ao invés de qualificar o debate e fazê-lo avançar, acabam produzindo novos mal-entendidos e avaliações frágeis das perspectivas que nelas são enquadradas.

\section{PostTIVISTA, FENOMENOLÓGICO-HERMENÊUTICA E CRÍTICO-DIALÉTICA: ASSIM É A PRODUÇÃO DO CONHECIMENTO EM EDUCAÇÃo FísICA?}

Em 1990, Souza e Silva defendeu a dissertação Mestrados em Educação Física no Brasil: pesquisando suas pesquisas, trabalho que ficou muito conhecido e cujo conteúdo e proposta analítica foram bastante empregados para caracterizar as pesquisas produzidas na área. Nesse texto, a pesquisadora empregou, influenciada por Gamboa 
(1987), o modelo do "esquema paradigmático" para discriminar as concepções de ciência que seriam predominantes na Educação Física. Sua análise popularizou a classificação que dividia as pesquisas em três matrizes teóricas: empírico-analítica, fenomenológicohermenêutica e crítico-dialética. A própria Souza e Silva (1997), em seu Doutorado, utilizou novamente o "esquema paradigmático" para analisar a produção do conhecimento circunscrita às dissertações de Programas de Pós-Graduação em Educação Física, no Brasil ${ }^{1}$.

Essa maneira de avaliar as pesquisas, muito importante no momento em que a Educação Física iniciava sua discussão de caráter epistemológico, vem sendo até hoje reproduzida, como evidencia a leitura de estudos, entre outros, da própria Souza e Silva (1998, 2005), mas, também de Gamboa (2007), Gamboa, Chaves e Taffarel (2007) e Chaves e Gamboa (2011). Embora reconheçamos o protagonismo desse tipo de estratégia, especialmente quando situada no contexto de seu surgimento, estamos interessados em discutir sua pertinência para caracterizar a produção do conhecimento da área² .

Consideramos essa classificação uma ferramenta analítica não pertinente para a compreensão do conhecimento produzido na/pela Educação Física brasileira. Os motivos dessa posição são arrolados na sequência. Entendemos que ela é insuficiente para caracterizar a complexidade, as nuanças e a diversidade teórica e política presente atualmente no âmbito de nossa discussão epistemológica. Não é possível enquadrar vários autores e suas contribuições, presentes na atividade epistemológica, em uma daquelas três matrizes. Exemplificamos com o caso do filósofo francês Michel Foucault, referência importante no debate epistemológico da Educação Física. Não podendo enquadrá-lo na tradição empírico-analítica ou na matriz crítico-dialética, resta-nos concluir, uma vez adotada a classificação

\footnotetext{
${ }^{1}$ Em seu doutorado, Souza e Silva (1997) analisou as dissertações dos Programas de PósGraduação em Educação Física da UFRGS, UNICAMP, UFMG, USP, UFSM e UFRJ, ampliando, assim, sua amostra em relação ao que investigara no mestrado (cujas análises se concentraram nas dissertações defendidas nos programas de Educação Física da USP, da UFSM e UFRJ). ${ }^{2}$ A classificação de Souza e Silva foi brevemente criticada por Vaz (2003), assim como alguns de seus argumentos por Ferreira Neto (2005). Tentativas de atualizar a classificação em tela podem ser obtidas em Ávila (2008) e Souza (2011).
} 
de Souza e Silva (1990, 1997, 1998, 2005), que os trabalhos de orientação foucaultiana na Educação Física seriam fenomenológicohermenêuticos? Os estudiosos que, na área, operam com as contribuições de Foucault sabem que sua obra possui tantas singularidades e especificidades que é difícil aceitar a classificação dos trabalhos, que nele se fundamentam, como de orientação fenomenológica ou hermenêutica. Embora Foucault tenha se relacionado com essas duas tradições, desenvolveu um trabalho que não se limita a elas ${ }^{3}$.

Esse tipo de dúvida não seria dirimido no caso de analisarmos os vários outros interlocutores que fundamentam as pesquisas que circulam no Grupo de Trabalho Temático (GTT) Epistemologia, do Colégio Brasileiro de Ciências do Esporte (CBCE), tomado novamente de forma exemplar, Jürgen Habermas, Jean François Lyotard, Friedrich Nietzsche, Norbert Elias, Edgard Morin, Boaventura de Souza Santos etc ${ }^{4}$. Seriam eles vinculados à fenomenologia? À hermenêutica? Ou seriam fenomenológicohermenêuticos? Aliás, a própria junção das tradições fenomenológicas e hermenêuticas é também problemática, pois são perspectivas bastante distintas entre si. Por exemplo, o trabalho de dois grandes nomes dessas tradições, respectivamente, Merleau-Ponty e Gadamer, são tão radicalmente diferentes que não vemos como reunir as pesquisas do campo, fundamentadas nesses autores, sob a designação fenomenológico-hermenêutica. Além disso, embora seja possível identificar hoje, na atividade epistemológica em Educação Física, uma tradição de estudos em torno da fenomenologia, especialmente a inspirada em Merleau-Ponty (Silvino Santin, Wagner Wey Moreira, Elenor Kunz, Mauro Betti, Terezinha Petrúcia Nóbrega entre outros

\footnotetext{
${ }^{3}$ No caso da fenomenologia, vale destacar, na esteira de Nalli (2006), a ambígua relação de Foucault com essa tradição, que vai de uma aproximação com Husserl, nos chamados escritos proto-arqueogenealógicos, até uma ruptura com a tradição, a partir da publicação de História da Loucura.

${ }^{4}$ Tomamos como referência o levantamento realizado por Nóbrega (2005) a respeito dos interlocutores que, já na década de 1990, embasavam os textos/pesquisas no âmbito daquele GTT.
} 
pesquisadores), não existe, na área, uma tradição de estudos propriamente hermenêuticos ${ }^{5}$. Só recentemente alguns pesquisadores têm feito esforços inéditos nessa direção, com destaque para Fensterseifer (2009, 2010) e Rezer (2010). O que dizer, então, desse quadro há vinte anos, quando o campo era menos diversificado, do ponto de vista teórico, do que é no momento?

Os problemas também existem no caso da matriz empíricoanalítica. Segundo argumenta Souza e Silva (1997, p. 154), existem nas dissertações analisadas visões empiristas, funcionalestruturalistas e sistêmicas de Homem. Todas elas, porém, "[...] pautadas em princípios epistemológicos e filosóficos cujas raízes mais profundas estão no positivismo." Continuar rotulando de positivistas os colegas que realizam pesquisas a partir do arcabouço teóricometodológico das ciências naturais só é possível se operarmos com uma visão bastante reducionista dessa tradição. Proceder dessa maneira implica desconsiderar as revoluções científicas (KUHN, 1987) que a própria corrente empírico-analítica experimentou ao longo dos últimos cinquenta anos, de modo que, após Popper, Kuhn, Bachelard, Feyerabend, Fleck, entre outros, é difícil aceitar a interpretação caricatural que está pressuposta nas reproduções do "esquema paradigmático" que fundamenta a análise de Souza e Silva (1990, 1997, 1998, 2005). O campo da matriz empírico-analítica é tão plural e complexo na atualidade que coloca em dúvida a viabilidade de tal classificação e mesmo de sua proficuidade, conforme a caracterização que Souza e Silva (1990, 1997, 1998, 2005) oferece em seus trabalhos. Embora possamos questionar até que ponto esses avanços têm sido incorporados pelos autores que operam no âmbito da tradição empírico-analítica em Educação Física, devemos ser mais

\footnotetext{
${ }^{5} \mathrm{Em}$ 1990, quando Souza e Silva defendeu sua dissertação, a presença da tradição fenomenológica no campo ainda era incipiente e eram escassos os estudos com base na hermenêutica. Além disso, no trabalho de sua tese de doutoramento, as dissertações que Souza e Silva (1997) caracterizou como fenomenológico-hermenéuticas, não operavam, tecnicamente falando, nem com a fenomenologia, nem com a hermenêutica. Essas dissertações privilegiavam os seguintes autores: "Piaget (43 vezes); Freire (42 vezes); Gadotti (37 vezes); Saviani (36 vezes); Barros, Nelson (33 vezes); Pellanda (31 vezes); Fernandes, J. L. (30 vezes); McLaren (28 vezes); Laglande (27 vezes); Silva, J. B. F. (26 vezes)" (SOUZA E SILVA, 1997, p. 169). Isso, por si só, coloca em xeque a estratégia de classificar as dissertações e teses em uma matriz que seria fenomenológico-hermenêutica.
} 
cautelosos em associar, como faz Souza e Silva (1990, 1997, 1998, 2005), essa perspectiva ao positivismo, mesmo porque a tradição empírico-analítica tem uma história que é anterior (e ultrapassa) ao próprio desenvolvimento do positivismo.

Outra característica presente na classificação proposta por Souza e Silva (1990, 1997, 1998, 2005), e que não é questionada e por aqueles que a reproduzem na atualidade, é a pressuposição de que é possível estabelecer o nível de criticidade das matrizes teóricas que embalam as pesquisas na área. Parece-nos, também, não proceder, o julgamento de valor feito a partir da matriz de análise a respeito do grau de criticidade de uma determinada produção do conhecimento. Um primeiro aspecto questionável em relação a esse procedimento diz respeito ao fato de se atribuir ou reivindicar para os estudos empírico-analíticos criticidade no sentido de questionar a realidade social. Isso simplesmente não faz sentido; um segundo aspecto questionável diz respeito ao pressuposto de que uma determinada teoria possui a prerrogativa de "desvelar" a realidade, portanto, permitiria acesso ao "real" e seria capaz, assim, de nos conduzir à verdade e, por isso, seria crítica. Em que consiste esse poder? Como validar os critérios que permitem esse julgamento? A partir daquilo que se chamou de "virada linguística", cresce o entendimento, no campo dos estudos epistemológicos, que esse conceito de verdade não se sustenta.

Além de continuar a ser empregada para caracterizar a produção do conhecimento em Educação Física, a classificação proposta por Souza e Silva (1990, 1997, 1998, 2005) vem passando por algumas atualizações, em uma tentativa de se adequar à pluralização teórica característica da atividade epistemológica em Educação Física. É possível identificar a emergência, diz a crítica, de outros paradigmas, como os "emergentes" ou da "complexidade" (GAMBOA; CHAVES; TAFFAREL, 2007), bem como a sugestão mesmo de outra classificação, que expressaria uma nova tendência na produção do conhecimento em Educação Física (ÁVILA, 2008): os a) empiristas, que correspondem à antiga matriz positivista; b) os idealistas; c) os paradigmas emergentes e antirrealistas; d) e os 
realistas científicos, que operam uma atualização da matriz críticodialética. Apesar das renovações propostas, algumas características permanecem da classificação anterior: há um crescente nível de criticidade, cujo ápice é a matriz crítico-dialética (realismo científico); os fundamentos mais verdadeiros, para a Educação Física, se encontram também nessa perspectiva; e, por fim, é a tradição do realismo científico seria mais progressista do ponto de vista político.

Nesse contexto, os defensores da matriz crítico dialética diluem a fronteira entre o que constitui as questões epistemológicas e o que representa sua posição política. Em última instância, é como se "tudo" ficasse subsumido à política ou, então, que a própria ciência justificasse as crenças políticas: "[...] a educação como ato político, a ciência engajada, a produção do conhecimento a partir de um ponto de vista de classe, não apenas mais revolucionário, mas por isso mesmo mais verdadeiro." (VAZ, 2003, p. 122-123). Nessa indistinção, não sãos as questões teóricas/filosóficas a fundamentar as apostas políticas, mas, sim, o inverso, já que "[...] pode-se afirmar que o desenvolvimento da ciência subordina-se ao Projeto Histórico e às relações econômicas predominantes por ele estabelecidas." (TAFFAREL; ALBUQUERQUE, 2010, p. 43). Pressuposto nesse entendimento está a ideia de que o verdadeiro significado de uma visão científica ou filosófica consiste em suas implicações políticas ou, então, na sua subordinação ao "projeto histórico". Em outros termos, o quadro de referência supremo para julgar um filósofo ou uma ciência é político. Nessas condições, a política precede à epistemologia, determinando, mesmo, seus rumos ${ }^{6}$.

Nas atualizações vigentes, os novos paradigmas que escapam à classificação empírico-analítica, fenomenológico-hermenêutica e crítico-dialética são tratados como "modismos" contra os quais se desencadeiam reações (CHAVES; GAMBOA, 2011; TAFFAREL; ALBUQUERQUE, 2010; GAMBOA, 2010). Geralmente, tais

\footnotetext{
${ }^{6}$ Embora, como adverte Bracht (2003), a política ganhe preeminência no contexto em que está desacreditada a possibilidade de uma instância fundamentadora que decrete, por meio de atos epistemológicos, qual a Verdadeira Educação Física, não deveríamos borrar, de uma vez por todas, as fronteiras que distinguem a epistemologia da política e vice-versa.
} 
perspectivas são rotuladas de pós-modernas, o que acaba produzindo outra polarização mais geral: os modernos e os pós-modernos. Trataremos doravante das reações ao que se supõe ser pósmodernismo.

\section{REAÇões AO PÓS-MOdERNISMO NA EdUCAÇão FísICA ${ }^{7}$}

Em 2008, por ocasião do IV "Colóquio de Epistemologia da Educação Física", o pós-modernismo esteve no centro das atenções na atividade epistemológica da área, como evidencia a temática central do evento ("Epistemologias, teorias do conhecimento na pesquisa em Educação e Educação Física: as reações aos pósmodernismos"). Este título já pressupõe o tipo de tratamento que parece ser reservado, por alguns interlocutores, à discussão: é preciso reagir à presença dos (supostamente) pós-modernos na atividade epistemológica em Educação Física. Segundo Taffarel e Albuquerque (2010, p. 12), "É necessário avançar, reagir, resistir, através de rupturas e saltos qualitativos, para novas sínteses em patamares teórico-práticos mais elevados, superando os desvios teóricos, rompendo ilusões, lutando contra o fetichismo [...]." Esse debate tem levado a uma polarização: de um lado, os modernos, representados, no caso da reação aqui analisada, pela matriz críticodialética (ou pelo realismo científico), para os quais o "modo de produção" continua sendo uma chave de leitura privilegiada para a crítica do capitalismo; de outro lado, os simpatizantes das perspectivas classificadas como pós-modernas, que supostamente abandonam, segundo a crítica, o projeto moderno e suas principais "bandeiras" (emancipação, liberdade, igualdade etc.). Esse tipo de polarização tem sido infrutífera. Considerar uma abordagem teórica como "desvio" pressupõe a existência de uma referência que sirva de medida para essa avaliação e julgamento e, com isso, essa perspectiva se coloca como aquela que possui um acesso privilegiado ao real, pressupondo de uma objetividade que dispensa o sujeito.

\footnotetext{
${ }^{7}$ Embora possamos identificar na literatura atinente à temática, autores que diferenciam pósmodernismo de pós-modernidade, vamos utilizar a primeira designação, pois é assim que têm sido empregada, recentemente, na Educação Física.
} 
Vejamos como se impinge a alguns autores a classificação de pós-modernos. Lyotard, signatário do conhecidíssimo livro A condição pós-moderna (2004), talvez a primeira obra a conferir um tratamento propriamente filosófico à questão, conceitua o pós-moderno, fundamentalmente, como uma incredulidade em relação aos metarrelatos da modernidade ou aos seus metadiscursos filosóficometatísicos. Após a publicação do livro, em 1979, Lyotard passa a argumentar que, em vez de utilizar o prefixo "pós", mais interessante seria falar em uma reescrita da modernidade. Afirma o filósofo (1990) que utilizara o termo de forma provocativa, não tanto para defender que a pós-modernidade seria uma nova era. Tratava-se, para ele, de uma reescrita de alguns traços reivindicados pela própria modernidade e, antes de tudo, da sua pretensão em encontrar legitimidade no projeto de emancipação de toda a humanidade com a ciência e a técnica. Ele faz questão, inclusive, de destacar que essa reescrita da modernidade estaria, desde há muito, em curso na própria modernidade. Lipovetsky (2004) observa ser a expressão pósmoderna, repetidas vezes por ele utilizada, ambígua, desajeitada e vaga. Para ele, se há vinte anos o conceito nos dava oxigênio, sugerindo o novo, tratar-se-ia já de um rótulo cheio de rugas, esgotado em sua capacidade de expressar o mundo que se anunciava. Como no caso de Lyotard, Lipovetsky jamais pressupôs que o pós-moderno representasse o fim da modernidade.

Se o pós-moderno pode ser também lido como uma reescrita da modernidade (e não seu abandono) ou, então, se apresenta como uma radicalização do próprio projeto moderno (Lipovestky), qual a razão de reagirmos a ele na atividade epistemológica da Educação Física? De igual modo, por que de antemão considerar que as perspectivas de Lyotard e Lipovetsky (e muitos outros considerados pós-modernos que estão entre nós) são "modismos" ou "imposturas intelectuais"8 que necessitam de algum tipo de reação? Se o trabalho desses autores pode ser criticado em vários pontos, a prévia

\footnotetext{
8É inevitável lembrar, em relação ao uso deste termo, o sobejamente conhecido "caso Sokal" e da polêmica resultante. Conferir, a esse respeito, Sokal e Bricmont (1999).
} 
desqualificação ("modismos" ou "imposturas intelectuais") não ajuda na exposição dos seus pontos mais frágeis, impedindo a conversação entre perspectivas diferentes.

Temos ainda mais razões para duvidar da utilidade do emprego dessa expressão na compulsão classificatória, se observarmos a lista de autores que, normalmente, são chamados de pós-modernos na discussão epistemológica do campo. Por exemplo, Foucault, Derrida e Rorty, sem escreverem afirmativamente sobre o tema ou mesmo se reconhecerem nessa condição, são interpretados como pósmodernos. Será isso adequado? Tomemos em análise, mais uma vez, o caso de Foucault. O filósofo francês, em artigo no qual faz um comentário sobre o célebre texto de Kant sobre o que seria o Iluminismo/Esclarecimento (Beantwortung der Fragung: Was ist Aufklärung?), destaca como, no filósofo alemão, o pensamento se confronta com uma situação histórica concreta, voltando-se ao seu presente, à sua atualidade: o que se passa no momento em que vivemos? O que hoje aparece como tarefa, como acontecimento? Ao colocar essas indagações à sua própria atualidade, não há, em Foucault (2005), nenhum diagnóstico a respeito do pós-moderno, nem mesmo uma postura de abandono em relação à modernidade. Faria mais sentido, com Foucault, perguntar: o que é esse movimento que nos precedeu e ao qual ainda pertencemos, denominado Aufklärung? Além disso, e ao contrário do que a crítica a ele costuma atribuir, Foucault tece loas ao que considera ser o traço mais característico da modernidade: a atitude crítica. E com essa atitude ele quer dizer um modo de relação com respeito à atualidade, um etos filosófico que se pode caracterizar como uma crítica permanente de nosso ser histórico. Esse etos crítico, diz Foucault (2005), implica em abandonar a alternativa (intelectual e política) - que ele considera simplista e autoritária - de estar contra ou a favor do Iluminismo/ Esclarecimento (Aufklärung), mas mais bem se caracteriza como uma atitude limite: não se trata de um comportamento de rechaço, mas da necessidade de permanecer nas fronteiras... do próprio Esclarecimento. 
No caso de Rorty, outro exemplo entre os intelectuais contemporâneos demarcados como pós-modernos (também na Educação Física), a situação não é muito diferente pois, além de dizer que o termo é infeliz e que causou muita confusão (RORTY, 1997a), faz questão de destacar que "Não há, em resumo, nada errado com as esperanças do Iluminismo, as esperanças que criaram as democracias ocidentais. $\mathrm{O}$ valor dos ideais do Iluminismo, para nós, pragmáticos, é justamente o valor de algumas instituições e práticas que eles criaram." (RORTY, 1997a, p. 51). Em texto mais recente, após tantas associações de seu nome ao rótulo, ele nos oferece a seguinte descrição:

Alguns intelectuais contemporâneos, especialmente na França e na Alemanha, consideram óbvio que o Holocausto deixou claro que as esperanças de liberdade humana surgidas no século XIX são obsoletas - que agora nós, pós-modernistas, sabemos que o projeto do Iluminismo está condenado. Mas até mesmo esses intelectuais, em seus momentos menos discursivos e sentenciosos, dão o melhor de si para levar adiante esse projeto. E assim deveriam fazer, pois ninguém apareceu com um projeto melhor. Não apaga as lembranças do Holocausto dizer que nossa resposta a ele não deveria ser a afirmação de ter adquirido uma nova compreensão da natureza ou da história humana, mas, em lugar disso, o desejo de nos recuperar e tentar novamente. (RORTY, 2005b, p. 210-211).

Assim sendo, não deixa de ser surpreendente a repulsa que os chamados pós-modernos têm experimentado em determinados segmentos do debate epistemológico da área, em especial no âmbito da tradição crítico-dialética. No extremo, qualquer ponderação crítica ao projeto moderno ou, então, às perspectivas teóricas que foram nevrálgicas à sua fundamentação, corre o risco de ser vista como pós-moderna.

As dúvidas aumentam ainda quando se analisam as características empregadas para se definir o pós-modernismo e, consequentemente, aqueles autores como pós-modernos. Seguem alguns exemplos: 
Os jogos da pós-modernidade apresentam-se de diversas formas, desde a crítica à racionalidade moderna que propõe diversas formas de articulação entre a teoria e a prática, passam pela defesa de um irracionalismo que prega a desconexão da prática com as razões universais (Rorty, 2000), a proposta da 'desconstrução' dos discursos, da linguagem, das palavras e dos referentes, separando-os dos contextos e dos autores (pós-estruturalismos) e ainda, valorizando a centralidade da linguagem, até o ponto de torná-la 'o objeto' de uma teoria do conhecimento (gnosiologia), separada de referentes e de realidades externas à linguagem (ontologia), defendendo um idealismo estremo [sic], quando o imaginário, as representações, as ideias, as categorias, as palavras antecedem às coisas e às experiências. (GAMBOA, 2010, p. 79).

[...] o irracionalismo proclamado pelos pósmodernismos se situa dentro da problemática da possibilidade do conhecimento quando, com base num renovado ceticismo, anuncia a difícil tarefa de estabelecer a relação entre a realidade, a representação mental e as palavras. É impossível estabelecer uma relação direta entre as palavras e as coisas (Foucault, 1981). É necessário denunciar o mentalismo (a representação das coisas na mente) e resgatar a relação pragmática das palavras, sem precisar passar pelos universais (Rorty, 1994). Na defesa do ceticismo filosófico, limita-se à possibilidade da cognição humana e de assegurar como objeto dessa cognição, apenas às palavras. $\mathrm{O}$ conhecimento pleno das coisas ou da realidade não é possível. Somente é possível conhecer os discursos, a linguagem, o texto e não sua relação com os referentes, com as intenções do autor e com os contextos da sua elaboração (o giro linguístico) (GAMBOA, 2010, p. 82, grifo do autor).

Situamos o contexto conjuntural e estrutural da crise para justificarmos a relevância das reações às teorias pós-modernas - ao irracionalismo, aos 'giros' ou 'viradas' idealistas -, imposturas intelectuais e recuo teórico que vem desarmando a classe trabalhadora 
no campo e na cidade, contribuindo para a alienação e para a contra-revolução (TAFFAREL; ALBUQUERQUE, 2010, p. 9).

Explicitamos o que é o irracionalismo, o pósmodernismo, os 'giros' ou 'viradas' idealistas e as reações daí advindas, questionando conceitos, explicitando interesses subjacentes à defesa da irracionalidade, do subjetivismo, dos particularismos, e do fragmentarismo, levantando hipóteses sobre o status da teorização na Educação no Brasil (TAFFAREL; ALBUQUERQUE, 2010, p. 11$)^{9}$.

As passagens apresentam uma descrição da filosofia desses autores que não encontra correspondência na letra de seus textos. Nossas descrições das filosofias de Foucault e Rorty, por exemplo, não identificam argumentos que seriam irracionalistas ou céticos. Assim, perguntamo-nos: as acusações de irracionalismo e ceticismo se sustentam quando contrapostas a outras leituras dos livros referenciados nas citações acima? Não identificamos nem mesmo como suas filosofias poderiam pressupor, mesmo à revelia e de maneira velada, ceticismo ou irracionalismo. Da mesma forma, não encontramos qualquer relação instrutiva entre o tipo de "virada" linguística que cada um desses dois autores praticou e o que a crítica que reage ao pós-modernismo chama de "virada" idealista. O que uma perspectiva tem a ver com a outra? O que há de idealismo filosófico nos "giros" linguísticos? Como isso se manifesta nos textos dos "pós-modernos" Foucault e Rorty? Rotular de idealistas as perspectivas que, em Filosofia, praticaram os "giros" linguísticos, acusando-as de tornar impossível o conhecimento pleno da realidade, significa desconsiderar que idealismo e "giro" linguístico nada têm em comum, pois são tradições distintas não apenas historicamente, mas, também, em seus pressupostos epistemológicos. Não há como,

\footnotetext{
${ }^{9} \mathrm{~A}$ essas considerações juntam-se outras, de acordo com as quais o pós-moderno representaria o fim da história, a morte da razão, o colapso do pensamento crítico, a transformação da realidade em ficção, o niilismo, a impossibilidade da verdade, carregando, consigo, uma agenda neoconservadora e desmobilizadora de processos de transformação social (TAFFAREL; ALBUQUERQUE, 2010; GAMBOA, 2010).
} 
nesse caso, realizar tal cotejamento. Portanto, insistir nesse ponto de vista só é possível ao preço de um equívoco interpretativo, que resulta de um (pré)conceito teórico em relação ao que os críticos do pós-moderno consideram ser "imposturas teóricas", "recuos" ou "desvios" da teoria. Em condições como essas, só pode ser inapropriada a articulação entre pós-modernismo, "viradas lingüísticas" e idealismo (TAFFAREL; ALBUQUERQUE, 2010; GAMBOA, 2007, 2010), seja porque os autores que praticaram os "giros" jamais se assumiram como pós-modernos, seja porque aquilo que caracteriza tais "giros", em Filosofia, em nada se assemelha às acusações, realizadas pelos críticos, de idealismo, irracionalismo, ceticismo epistemológico, político etc.

No contexto das reações empreendidas, em Educação Física, ao pós-modernismo, merece destaque o que Gamboa (2007, 2010), Ávila (2008), Taffarel eAlbuquerque (2010) e Ávila e Ortigara (2007), apresentam como a alternativa às "viradas" linguísticas (vale dizer, ao pós-modernismo): a necessidade do "giro" ou "virada" ontológica. Segundo Gamboa (2007, p. 2):

A superação dessa tensão se dá através da 'ontologia'. A identidade da ciência está em discutir o que é a realidade, o que é o mundo (ser ontológico). A base da ciência está no conhecimento dos fenômenos, como eles são, se apresentam e se revelam e não nas formas como o homem representa ou atua sobre o mundo.

Destacamos dois aspectos que tornam sem sentido a reação pretendida ou, mesmo, a necessidade de a ontologia preceder a epistemologia. Em primeiro lugar, os que clamam pela virada ontológica utilizam como justificativa para essa inflexão o fato de os "giros" linguísticos terem provocado a morte do real, a impossibilidade da objetividade e da verdade como correspondência inscrita na realidade. Normalmente, utilizam a expressão antirrealismo para caracterizar o "vácuo" aberto pelo colapso do real. Na medida em que essa é uma hipótese que não se sustenta quando lemos o que os praticantes dos giros escreveram sobre a relação entre a linguagem e realidade, a própria necessidade de uma reação em "defesa da 
realidade" (da ontologia) torna-se descabida, sem propósito. Nenhum dos filósofos mencionados nas passagens retiradas dos textos de Gamboa, Taffarel e Albuquerque, praticaram idealismo linguístico, ou seja, a tese, também criticada por Rorty (1997b), segundo a qual "não há realmente nada" acerca do que se falar antes de começarmos a falar, ou seja, que os objetos (inclusive do mundo natural) só adquirem existência quando pronunciados por alguma linguagem. Nem Foucault nem Rorty consideraram que o real seja incognoscível ou que, até falarmos dele, a realidade não exista. Ainda segundo Rorty, essa celeuma (que opõe realistas e antirrealistas) é debate do início do século vinte e que, portanto, não deveria mais preocupar os filósofos de cem anos depois, já que "Ninguém acha que existe uma cadeia de causas que torna as montanhas um efeito dos pensamentos ou das palavras." (RORTY, 2005a, p. 75). Se alguém não acredita que sua existência é anterior, possivelmente é porque não está em condições de participar dos jogos de linguagem que empregam as palavras estrelas, árvores ou montanhas. Mas o fato de essa existência ser anterior e intransitiva de nada serve para dar sentido à pergunta sobre o que seriam as árvores e as estrelas fora de suas relações com outras coisas, à parte de nossos enunciados sobre elas. Para Rorty, os que veem um abismo entre a linguagem e o mundo operam com um conceito de linguagem que a considera um meio de representação ou espelhamento do real. Vamos ler Rorty (2007, p. 36) a respeito disso:

Posso explicar o que pretendo dizer com 'meio' assinalando que a imagem tradicional da situação humana tem sido a de que os seres humanos não são simples redes de crenças e desejos, mas seres que têm crenças e desejos. A visão tradicional é que há um eu nuclear capaz de examinar essas crenças e desejos, decidir entre eles, usá-los e se expressar por meio deles. Ademais, essas crenças e desejos podem ser criticados não apenas por referência a sua capacidade de serem coerentes entre si, mas em referência a algo externo à rede da qual eles são fios. As crenças, segundo essa visão, são criticáveis por não corresponderem à realidade. Os desejos são criticáveis por não corresponderem à natureza 
essencial do humano - por serem 'irracionais' ou 'antinaturais'. Temos assim uma imagem do núcleo essencial do eu, num dos lados da rede de crenças e desejos, e da realidade, no outro. Nessa imagem, a rede é o produto de uma interação entre os dois, que alternadamente expressa um e representa o outro. Essa é a imagem tradicional do sujeito-objeto que o idealismo tentou e não conseguiu substituir, e que Nietzsche, Heidegger, Derrida, James, Dewey, Goodman, Sellars, Putnam, Davidson e outros tentaram substituir, sem se enredarem nos paradoxos dos idealistas.

Em segundo lugar, a tese de que estaríamos vivendo, no debate epistemológico contemporâneo, uma supressão da ontologia, é questionável, ao menos se pensarmos nela a partir de um vocabulário diferente daquele que é defendido pela tradição crítico-dialética em Educação Física (ALMEIDA; VAZ, 2010). Podemos exemplificar recorrendo, desta vez, ao filósofo alemão Gadamer (2007). Não é verdade que o "giro" do tipo hermenêutico tenha abolido o vocabulário ontológico. Conforme podemos apreender da perspectiva gadameriana, a hermenêutica é compreendida como o básico estarem-movimento do Ser-aí (Dasein) que constitui a sua finitude e a sua historicidade e, por isso, inclui o conjunto da sua experiência do mundo. Assim, o estudo da hermenêutica seria o estudo do Ser e, como diz Gadamer (2007), Ser que pode ser compreendido é linguagem. Esta conhecida sentença revela, por um lado, o nexo entre ontologia e linguagem e, por outro, que a compreensão é um modo de Ser, e não um modo de conhecimento (portanto, a ontologia precederia à epistemologia, como pretende a reação ontológica desejada por aquela crítica). A viragem ontológica de Gadamer está enraizada em uma ontologia existencial que anuncia o erro da crença em um mundo real que seja independente da linguagem. Esse absolutismo ontológico, por sua vez, é um eco distante da posição ontológica de Gadamer, para quem, aliás, a dicotomia entre linguagem e realidade, além de pressupor uma visão estreita da primeira, constitui um obstáculo à compreensão. Se a linguagem nos dá o mundo, então o inverso também é verdadeiro: o nosso mundo dános a linguagem. Assim, segundo as palavras do próprio filósofo, em 
[...] frente ao mundo que vem à fala nela, a linguagem não instaura, ela mesma, nenhuma existência autônoma. Não só o mundo é mundo apenas quando vem à linguagem, como a própria linguagem só tem sua verdadeira existência no fato de que nela se representa o mundo. A originária humanidade da linguagem significa, portanto, ao mesmo tempo, o originário caráter de linguagem do estar-no-mundo do homem. (GADAMER, 2007, p. 572)

A defesa de Gadamer da linguagem como revelação do mundo evita uma abordagem da ontologia que pressupõe um "mundo real" que limita e constringe a própria linguagem, abandonando, como consequência, uma compreensão que a vê como meio ou instrumento de representação, pelo qual a consciência se ligaria ao mundo, entendido como objeto daquela. $\mathrm{O}$ caráter de linguagem em que "[...] se dá a experiência do mundo precede a tudo quanto pode ser reconhecido e interpelado como ente." (GADAMER, 2007, p. 581).

Em função do que acabamos de descrever a respeito da relação entre ontologia e linguagem, temos mais razões para supor que o alardeado "vácuo do real", decorrente das "viradas" no campo, não resiste a uma análise mais cuidadosa da letra dos filósofos que praticam tais giros. Permite questionar, além disso, a tese segundo a qual estaríamos presenciando, em Educação Física, um recuo dos argumentos ontológicos, pressuposto indispensável para a pretendida revirada ontológica de base materialista (ALMEIDA; VAZ, 2010). $\mathrm{Na}$ tradição do giro hermenêutico, o vocabulário ontológico é tão atual quanto antes.

\section{Considerações finaIS}

Este artigo ofereceu uma redescrição de duas classificações presentes no debate epistemológico da Educação Física: uma que sugere três matrizes teóricas (empírico-analítica, fenomenológicohermenêutica e crítico-dialética) para caracterizar a produção científica do campo e a outra que dispõe em lados opostos modernos e pós-modernos. Procuramos demonstrar as insuficiências e os 
limites dessas duas classificações, argumentando que elas, por um lado, constrangem o pluralismo teórico que se busca construir na área a partir de uma desessencialização da verdade e, por outro lado, acabam promovendo a subordinação da ciência à política. Além disso, tais classificações acabam oferecendo descrições inapropriadas das perspectivas que nelas são "enquadradas", desconsiderando a própria letra dos textos dos autores em prol das teses que seus críticos pretendem ver corroboradas. Também procuramos desconstruir, no artigo, a associação dos "giros" ou "viradas" linguiísticos(as) ao pósmodernismo e ao idealismo, sugerindo que a reação ontológica em curso está fundada em premissas questionáveis.

As razões que apresentamos no texto nos levam a renunciar a essas duas classificações como modelo heurístico para caracterizar o atual debate epistemológico do campo ${ }^{10}$, uma vez que elas não fazem jus à complexidade teórica e política que marca, na atualidade, a atividade epistemológica em Educação Física. O pluralismo requerido fundamenta-se no abandono das pretensões de alcançar um vocabulário último e, ao admitirmos a falibilidade de todos os pontos de vista, mantém-se aberta a possibilidade de interpretações diversas da realidade, incitando-nos, por sua vez, à conversação e/ ou ao diálogo constante. Segundo essa perspectiva, quantos mais descrições disponíveis, mais oportunidade teremos para cotejar os vocabulários uns com outros e, assim, mais fácil será a decisão de ter que optar por algum sem precisar apelar a discursos fundacionistas de toda ordem. $\mathrm{O}$ que entendemos necessário ficar claro, seguindo sugestão de Fensterseifer e Gonzalez (2007, p. 30), "[...] é que em uma sociedade autônoma, democrática, as concepções de mundo, de ser humano, de sociedade, estão sempre em discussão no plano político, não há deliberação definitiva ('concepção verdadeira') a ser 'ensinada aos neófitos'."

\footnotetext{
${ }^{10}$ Não consideramos inadequado o uso de classificações para caracterizar a produção do conhecimento da área. Reconhecemos que elas ajudam o leitor neófito não somente a se situar no debate, mas, também, a caracterizá-lo em função das perspectivas que o compõem. Elas se tornam questionáveis quando, ao invés de liberar o pensamento, inibem-no, mantendo-o preso a estereotipias que exercem um poder simplificador sobre o que se pretende elucidar. Este é o caso, parece-nos, das classificações que nos dispusemos a analisar. O risco é a atividade epistemológica reduzir-se ao ato de classificar, entendendo que a produção de conhecimento se resumiria a isso.
} 
Para evitar os reducionismos criticados no manuseio das classificações, entendemos que mais importante seria realizar estudos pontuais e cuidadosos dos autores que circulam e fundamentam o debate epistemológico em Educação Física. Isso seria bom para nós e também para eles, evitando simplificações exageradas que podem levar facilmente a rotulações do tipo: irracionalistas, conservadoras, idealistas etc. Elas muito pouco contribuem para o avanço do debate. 
Epistemological Classifications in Physical Education: Redescreptions...

Abstract: This paper proposes a rediscreption of two popular epistemological classifications in Physical Education. The first one classifies the knowledge in three theoretical approaches (Empiric-Analytical, Phenomenological-Hermeneutical, Critic-Dialectical); the other one suggests an epistemological oppositions between modern and post-modern theories. The paper analyses the actuality of both positions in sense of the political and theoretical discussion in Physical Education. This analysis try to reach an advised understanding of some perspectives of those positions. After focusing limits and inadequateness of those classifications, refusing their clichés, the paper defends that the complexity and the sharing of different theories demand much more care in handing and interpretations of them.

Keywords: Physical Education. Epistemology. Postmodernism. Language.

\section{Clasificaciones Epistemológicas en Educación} Física: redescripciones

Resumen: El artículo ofrece una redescripción de dos clasificaciones epistemológicas muy difundidas en la Educación Física: a) una que considera la producción del conocimiento organizada en un eje de tres abordajes teóricos (empírico-analítica, fenomenológica-hermenéutica y crítico-dialéctica); b) la otra opone modernos a postmodernos en el debate epistemológico del área. El artículo analiza la actualidad de las dos posiciones en términos de la presente configuración teórica y política del campo de la Educación Física, así como bajo la posibilidad de una lectura más amplia de algunas de las perspectivas que componen dichas clasificaciones. Después de presentar los límites y insuficiencias de las clasificaciones, rechazando los clichés que de ellas se originan, el artículo argumenta que la complexidad ya las interpenetraciones de distintas teorías exigen más cuidado en su elaboración y uso.

Palabras clave: Educación Física. Epistemología. Posmodernismo. Lenguaje. 


\section{REFERÊNCIAS}

ALMEIDA, F. Q.; VAZ, A. F. Do giro lingüístico ao giro ontológico na atividade epistemológica em Educação Física. Movimento, Porto Alegre, v. 16, n. 3, p. 1128, jul./set. 2010.

ÁVILA, A. B. Pós-graduação em educação física e as tendências na produção do conhecimento: o debate entre realismo e antirrealismo. 2008. Tese (Doutorado em Educação) - Programa de Pós-Graduação em Educação, Universidade Federal de Santa Catarina, Florianópolis, 2008.

ÁVILA, A. B.; MULLER, H. V. O.; ORTIGARA, V. Ciência e ontologia: alguns apontamentos para refletir a pesquisa em educação física. In: CONGRESSO BRASILEIRO DE CIÊNCIAS DO ESPORTE/CONGRESSO INTERNACIONAL DE CIÊNCIAS DO ESPORTE, 15. e2., 2007, Recife. Anais... Recife: CONBRACE, CONICE, 2007.

BRACHT, V. Identidade e crise da educação física: um enfoque epistemológico. In: BRACHT, V.; CRISÓRIO, R. (Org.). A educação física no Brasil e na Argentina: identidade, desafios e perspectivas. Campinas: Autores Associados; Rio de Janeiro: PROSUL, 2003. p. 13-29.

CHAVES, M.; GAMBOA, S. A produção de conhecimento em EF/ Ciências do Esporte/ CE - qualidade $x$ quantidade: os desafios de uma experiência concreta. Palestra proferida no IV Fórum de Pós-Graduação em Educação Física do CBCE. Florianópolis, 2011.

CHAVES, M.; GAMBOA, S.; TAFFAREL, C. A pesquisa em educação física no Nordeste brasileiro (Alagoas, Bahia, Pernambuco e Sergipe), 1982-2004: balanço e perspectivas. Revista Brasileira de Ciências do Esporte, Campinas, v. 29, n.1, p. 89-106, set. 2007.

FENSTERSEIFER, P. Atividade epistemológica e educação física. In: NÓBREGA, T. P. (Org.). Epistemologia, saberes e práticas da educação física. João Pessoa: Editora da UFPB, 2006. p. 29-37.

Linguagem, hermenêutica e atividade epistemológica na educação física. Movimento, Porto Alegre, v. 15, n. 4, p. 243-256, out./dez. 2009.

Educação Física: atividade epistemológica e objetivismo. Filosofia e Educação: Revista Digital do Paidéia, Campinas, v. 2, n. 2, p. 99-110, out. 2010.

FENSTERSEIFER, P; GONZALEZ, F. Educação Física escolar: a difícil e incontornável relação teoria e prática. Motrivivência, Florianópolis, ano XIX, n. 28, p. 27-37, jul. 2007.

FERREIRA NETO, A. F. Leitura dos 20 e 25 anos do CBCE: política, comunicação e (in)definição do campo científico. In: FERREIRA NETO, A. (Org.). Leituras da natureza científica do CBCE. Campinas: Autores Associados, 2005. p. 3-26. 
FOUCAULT, M. Ditos e escritos: arqueologia das ciências e história dos sistemas de pensamento. Rio de Janeiro: Forense Universitária, 2005. v. 2

GADAMER, H. G. Verdade e método I: traços fundamentais de uma hermenêutica filosófica. Rio de Janeiro; Bragança Paulista: Vozes, Editora Universitária São Francisco, 2007.

GAMBOA, S. Epistemologia da pesquisa em Educação: estruturas lógicas e tendências metodológicas. 1987. Tese (Doutorado em Educação) - Programa de Pós-Graduação em Educação, Universidade Estadual de Campinas, Campinas, 1987.

Reações ao giro lingüístico: o "giro ontológico", ou o resgate do real independente da consciência e da linguagem. In: CONGRESSO BRASILEIRO DE CIÊNCIAS DOESPORTE/CONGRESSO INTERNACIONALDECIÊNCIASDO ESPORTE, 15. e 2., 2007, Recife. Anais... Recife. CONICE, CONBRACE, 2007.

O debate da pós-modernidade: as teorias do conhecimento em jogo. Filosofia e Educação: Revista Digital do Paidéia, Campinas, v. 2, n. 2, p. 74-98, out. 2010.

KUHN, T. A estrutura das revoluções científicas. São Paulo: Perspectiva, 1987.

LIPOVETSKY, G. Os tempos hipermodernos. São Paulo: Barcarol, 2004.

LYOTARD, J. F. O inumano: considerações sobre o tempo. Lisboa: Estampa, 1990.

A condição pós-moderna. Rio de Janeiro: José Olympio, 2004.

NALLI, M. Foucault e a fenomenologia. São Paulo: Loyola, 2006.

NÓBREGA, T. P. Desafios da ciência, reflexão epistemológica e implicações para a educação física e ciências do esporte. In: FERREIRA NETO, A. (Org.). Leituras da natureza científica do CBCE. Campinas: Autores Associados, 2005. p. 91-125.

REZER, R. O trabalho docente na formação inicial em Educação Física: reflexões epistemológicas... 2010. Tese (Doutorado em Educação Física) - Programa de Pós-Graduação em Educação Física, Universidade Federal de Santa Catarina, Florianópolis, 2010.

RORTY, R. Objetivismo, relativismo e verdade. Rio de Janeiro: Relume-Dumará, 1997a.

Esperanza o conocimiento? Uma introducción al pragmatismo. Buenos Aires: Fondo de Cultura Econômica, 1997b.

Verdade e progresso. Barueri: Manole, 2005a. 
Realidade objetiva e comunidade humana. In: SOUZA, J. C. (Org.). Filosofia, racionalidade e democracia: os debates Rorty e Habermas. São Paulo: Unesp, 2005b. p. 213-230.

Contingência, ironia e solidariedade. São Paulo: Martins Fontes, 2007.

SOKAL, A.; BRICMONT, J. Imposturas intelectuais: o abuso da ciência pelos filósofos pós-modernos. Rio de Janeiro: Record, 1999.

SOUZA E SILVA, R. V. Mestrados em educação física no Brasil: pesquisando suas pesquisas. 1990. Dissertação (Mestrado em Ciência do Movimento Humano) - Programa de Pós-Graduação em Ciência do Movimento Humano da Universidade Federal de Santa Maria, Santa Maria, 1990.

SOUZA E SILVA, R. V. Pesquisa em educação física: determinações históricas e implicações epistemológicas. 1997. Tese (Doutorado em Educação) - Programa de Pós-Graduação em Educação, Universidade Federal de Campinas, Campinas, 1997.

. As ciências do esporte no Brasil nos últimos 20 anos: contribuição da pósgraduação stricto senso. Revista Brasileira de Ciências do Esporte, Florianópolis, p. 54-64, set. 1998. número especial

. O CBCE e a produção do conhecimento em educação física em perspectiva. In: FERREIRA NETO, A. (Org.). Leituras da natureza científica do CBCE. Campinas: Autores Associados, 2005. p. 45-69.

SOUZA, J. P. M. Epistemologia da Educação Física: análise da produção científica do programa de pós-graduação da Faculdade de Educação Física da UNICAMP (1991-2008). 2011. Tese (Doutorado em Educação) - Programa de Pós-Graduação em Educação, Universidade Federal de Campinas, Campinas, 2011.

TAFFAREL, C. N. Z.; ALBUQUERQUE, J. O. Epistemologias e teorias do conhecimento em educação e educação física: reações aos pós-modernismos. Filosofia e Educação: Revista Digital do Paidéia, Campinas, v. 2, n. 2, p. 8-52, out. 2010.

VAZ, A. F. Metodologia da pesquisa em educação física: algumas questões esparsas. In: BRACHT, V.; CRISÓRIO, R. (Org.). A educação física no Brasil e na Argentina: identidade, desafios e perspectivas. Campinas: Autores Associados; Rio de Janeiro: PROSUL, 2003. p. 115-127.

Endereço para correspondência:

Valter Bracht

Rua Edson Queiroz do Vale,18

Cond. Mar Azul - Bairro Manguinhos

29173-079 Serra/ES

Recebido em: 24.04.2012

Aprovado em: 09.05.2012

lovimento, Porto Alegre, v. 18, n. 04, p. 241-263, out/dez de 2012. 
